\title{
A CAMPESINIDADE E O AGROHIDRONEGÓCIO EM MUCUGÊ, CHAPADA DIAMANTINA-BAHIA
}

\section{CAMPESINITY AND AGRICULTURAL BUSINESS IN MUCUGÊ, CHAPADA DIAMANTINA-BAHIA}

\author{
Débora Paula de Andrade Oliveira \\ Universidade Federal de Sergipe, Doutoranda no Programa de Pós-Graduação em Geografia, \\ São Cristóvão, SE. \\ deborapaulageografia@gmail.com \\ Sônia de Souza Mendonça Menezes \\ Universidade Federal de Sergipe, Docente no Programa de Pós-Graduação em Geografia, \\ São Cristóvão, SE. \\ soniamenoncamenezes@gmail.com
}

\section{Resumo}

O artigo aborda as configurações territoriais de Mucugê, Chapada Diamantina - Bahia, no contexto dos territórios rurais onde coexistem o agrohidronegócio e a campesinidade. Buscou-se refletir sobres a multiplicidade das territorialidades, por vezes conflitantes na realidade local. A metodologia está pautada na discussão dos referenciais teóricos concernentes à questão agrária, ao agrohidronegócio, à campesinidade e à agrobiodiversidade. Buscou-se sistematizar dados secundários relativos às condições sociais de vida da população local, além da elaboração de mapeamentos e pesquisas de campo in loco, que envolve observações diálogos e vivências. Na leitura da realidade em questão, constatou-se que o agrohidronegócio transformou os territórios de Mucugê, impondo lógicas capitalistas de trabalho na terra, todavia, ainda persistem formas alternativas de trabalho e vida pautados na sociabilidade camponesa. Os índices socioeconômicos locais repercutem as contradições sociais intrínsecas ao agrohidronegócio, nos quais foi possível comprovar que a enunciada riqueza e o desenvolvimento proclamado pelos defensores do agrohidronegócio raramente têm contribuído para a melhoria das condições de vida da população local. A criação de territorialidades pelos sujeitos da agricultura familiar camponesa constitui-se como uma estratégia de reprodução social e permanência no campo.

Palavras-chave: Agricultura Familiar Camponesa. Agrobiodiversidade. Agrohidronegócio. Campesinidade.

\section{Abstract}

The article deals with the territorial configurations of Mucugê, Chapada Diamantina Bahia, in the context of rural territories where hydro-agribusiness and peasantry coexist. We tried to reflect on the multiplicity of territorialities, sometimes conflicting in the local reality. The methodology is based on the discussion of theoretical references concerning 
the agrarian question, agribusiness, peasantry and agrobiodiversity. We sought to systematize secondary data related to the social conditions of life of the local population, in addition to the elaboration of mappings and field surveys in loco, which involves dialogical observations and experiences. In reading the reality in question, it was found that agribusiness transformed the territories of Mucugê, imposing capitalist logics of work on the land, however, alternative forms of work and life based on peasant sociability still persist. The local socioeconomic indexes reflect the social contradictions intrinsic to hydro-agribusiness, in which it was possible to prove that the enunciated wealth and development proclaimed by hydro-agribusiness defenders have rarely contributed to the improvement of the living conditions of the local population. The creation of territorialities by the subjects of peasant family farming constitutes a strategy for social reproduction and permanence in the countryside.

Keywords: Family Peasant Agriculture. Agrobiodiversity. Hydro-agribusiness. Peasantry.

\section{Introdução}

A leitura geográfica acerca da questão agrária na atualidade exige a compreensão das múltiplas nuances que o território assume para os diferentes segmentos e sujeitos sociais que o constroem e se transformam nesse processo, à medida que criam territorialidades em seus contextos de persistências e coexistências.

Na compreensão dos territórios rurais de Mucugê, Chapada Diamantina - Bahia, busca-se enveredar pela miríade de significações e processos que transitam entre relações de poder instituídas de modo vertical via apropriação do território pelo poder do capital privado, apoiado pelo Estado, que corresponde ao agrohidronegócio nesse município e, antagonicamente, pelas relações sociais e simbólicas que dão sentido aos territórios de vida para os agricultores familiares camponeses locais que compõem a campesinidade.

Localizada na região central do Estado da Bahia, Mucugê apresenta uma extensão de $2.462,153 \mathrm{~km}^{2}$. O território é marcado por uma complexa estrutura fundiária onde se sobrepõem espaços dominados pelo agrohidronegócio, marcados pelo latifúndio formado por empreendimentos capitalistas, os territórios instituídos como unidades de conservação pelo Estado e os territórios da agricultura familiar camponesa. Tais aspectos se materializam de modo diverso nos espaços rurais de Mucugê, onde convergem interesses e significações, por vezes, incongruentes.

As contradições, conflitualidades e significações se evidenciam nos espaços rurais de Mucugê: a expansão do agrohidronegócio, onde a terra é somente recurso, entendido numa perspectiva mercadológica de acumulação capitalista, e, numa lógica adversa, persiste a agricultura familiar camponesa, alicerçada no valor moral e ético da terra para 
a manutenção da vida dos sujeitos sociais do campo. Em face disso, o artigo tem como objetivo refletir sobre as configurações territoriais de Mucugê no contexto da coexistência entre o agrohidronegócio e a resistência da campesinidade presente nos territórios rurais desse município.

\section{Aspectos metodológicos}

A pesquisa está amparada numa perspectiva qualitativa de análise, cuja abordagem busca envolver os aspectos objetiváveis e (i)materiais da realidade em pauta. Para a consecução do estudo, primou-se pelas discussões teóricas pertinentes à realidade agrária no campo brasileiro, especialmente nos estudos sobre a questão agrária presente nas análises de Oliveira (2001, 2003) e Fernandes (2014), sobre o agrohidronegócio, fundamentado em Thomaz Junior $(2010$; 2017) e acerca das relações (i)materiais que permeiam a campesinidade, alicerçado na abordagem de Woortmann (1990), Brandão (1999), Carvalho (2013) e Almeida (2018). Tais autores, com diferentes enfoques e perspectivas, contribuem para a compreensão dos espectros plurais que atravessam os espaços rurais no Brasil.

No que tange aos procedimentos metodológicos, pautou-se no levantamento de dados secundários em órgãos oficiais, a exemplo do Instituto Brasileiro de Geografia e Estatística (IBGE) e do Instituto do Meio Ambiente e Recursos Hídricos (INEMA) para sistematização das informações em mapas e gráficos, além da pesquisa na imprensa local/nacional e nas fontes historiográficas. A análise desses dados tem sido permanentemente confrontada com a realidade observada nas pesquisas de campo, realizadas em paralelo.

A discussão das informações oriundas de tais fontes tem fomentado reflexões cujo desdobramento aponta para a compreensão das configurações territoriais de Mucugê em sua totalidade. Desse modo, o tópico apresentado a seguir tem como propósito evidenciar os alicerces teóricos que têm balizado a pesquisa.

\section{Campesinidade e agrohidronegócio: a multiplicidade de usos do território}

O território como expressão material e simbólica das relações socioespaciais pode ser lido e reinterpretado segundo os distintos processos sociais, históricos, econômicos e

culturais nele presentes. É possível vislumbrar o território tanto na perspectiva das relações de poder jurisdicionadas pelo Estado - como propõe Gotmann (2012[1975]) quanto condição e recurso à acumulação capitalista, conforme adverte Raffestin (1993). 
Há também que se considerar a dimensão mais subjetiva, imaterial e simbólica do território, que se constitui no espaço vivido permeado pelos sentimentos de pertencimento e afeto, como abordam Bonnemaison (2002), Haesbaert (1999) e Almeida (2018). Ancora-se na premissa de que a leitura da multiplicidade presente nessa dimensão do espaço reverbera nas diferentes direções analíticas construídas sobre o território. Logo, esses enfoques, ainda que essencialmente distintos, não são mutuamente excludentes.

Oliveira (2001) compreende que o território, no contexto da questão agrária, corresponde à síntese das contradições sociais, políticas e econômicas da expansão capitalista. Em sua análise de conjuntura acerca da relação contraditória estabelecida entre o camponês e o capitalismo, Oliveira (2001, p. 185) compreende que esse modo de produção atua “[...] na direção da implantação do trabalho assalariado, no campo em várias culturas e diferentes áreas do país".

A dominação do campo brasileiro pelo capital se expressa também sob a forma do agrohidronegócio. As reflexões acerca desse conceito foram propostas inicialmente por Mendonça e Mesquita (2007), que cunharam o conceito para analisar a inserção massiva do capital nos cerrados goianos sob o espectro da modernização da agricultura. Posteriormente, o conceito foi revisitado e ressignificado por Thomaz Junior (2010), que enfatizou a influência do Estado no favorecimento das infraestruturas destinadas à acumulação capitalista nos espaços agrários brasileiros. Ao retomar as discussões referentes a essa temática, o autor, em 2017, considera que dispor de terra e água de forma consorciada e ter o controle sobre esses bens permite que o capital obtenha as condições satisfatórias para a prática da irrigação. A despeito do uso dos recursos naturais, o agronegócio, outrossim, dispõe de recursos hídricos para a sua manutenção, com o uso de infraestruturas empreendidas com recursos públicos derivadas do Estado.

A expansão do agrohidronegócio, com a conivência do Estado, em diversas escalas, interesses e relações de poder, é responsável pelo estágio de degradação socioambiental dos sistemas naturais. Soma-se a isso a precarização extrema provocada pela exploração dos trabalhadores, que sofrem com a reprodução e ampliação das mazelas sociais produzidas e retroalimentadas pelas múltiplas conflitualidades no campo brasileiro. A elevação dos índices de concentração fundiária consiste num dos pilares do agronegócio, condição que acirra as tensões territoriais no campo. Thomaz Junior (2010; 2017) enfatiza que o agrohidronegócio é uma realidade no campo brasileiro, tendo em vista que, além de dispor dos favorecimentos de investimentos de natureza pública e 
privada, os resultados satisfatórios obtidos pelas grandes corporações capitalistas são potencializados pelo acesso às terras com melhores condições agricultáveis e logísticas.

Em Mucugê, referência empírica desta análise, observam-se as políticas de favorecimento do Estado ao agrohidronegócio com a construção da Barragem do Apertado, em 1998, na bacia do Rio Paraguaçu. Os recursos hídricos dessa infraestrutura pública são predominantemente direcionados aos grupos empresariais oriundos de diferentes escalas que, desde então, usufruem dessas águas. Todavia, nos últimos anos, esse recurso tem apresentado sinais de escassez.

Em face dessas conflitualidades macroestruturais e sistêmicas, intrínsecas ao modo de produção capitalista no campo, busca-se evidenciar também uma outra escala, aquela pertinente às singularidades experienciadas pelos sujeitos sociais que persistem em sua campesinidade e que fazem do campo seu território de trabalho e da vida. $\mathrm{Na}$ insígnia dos múltiplos significados envoltos na cotidianidade presente no campo, faz-se premente aguçar o olhar para desvendar os sentidos que permeiam as relações de pertencimento, identidade, memória e territorialidades intrínsecas à campesinidade dos sujeitos sociais que vivem da terra.

Tal desafio analítico consiste em considerar os aspectos estruturais, contraditórios e macroescalares que compõem os territórios rurais, sem, contudo, negligenciar a perspectiva dos sujeitos sociais, com suas intencionalidades, os simbolismos e as subjetividades que atravessam suas vivências no território. Compreende-se, em conformidade com Fernandes (2014), que o agricultor familiar e o camponês são os mesmos sujeitos sociais, ainda que lidos sob lupas teóricas diversas. Para o autor:

[...] el término campesino y agricultura familiar con el mismo sentido. Utilizar los dos conceptos juntos o separados, pero refiriéndo se siempre a la organización familiar, comunitaria, asociativa o cooperativa es coherente. Lo que se debe evitar es separarlos por medio de falsas definiciones como incompleto, atrasado, superado, antiguo, etc. [...] Es um sujeto histórico perenne que lucha para ser el mismo. (FERNANDES, 2014, p. 20).

O agricultor familiar camponês é o sujeito social e histórico que tem na terra e o seu território de vida e trabalho, haja vista que nela se tem a possibilidade da reprodução do seu modo de vida, pleno de conteúdos sociais e culturais, que extrapolam a lógica econômica da produção, circulação e do consumo no capitalismo. Concorda-se com K. 
Woortmann (1990), quando propõe a análise do campesinato como um valor moral, um ethos particular que caracteriza um modo de existência e sociabilidade.

Seguindo essa abordagem, Menezes afiança que: “A terra, para os agricultores familiares, é considerada como terra de trabalho lugar no qual o homem tem o seu trabalho realizado, independência e a sua realização como pessoa humana" (2009, p.56). A lógica simbólica do trabalho no campo é permeada de subjetividades que delineiam as significações do território, transformada em condição para vida, sociabilidade e trabalho na e $d a$ terra (WOORTMANN; WOORTMANN, 1997). Trata-se de um bem essencial à permanência e à manutenção de um modo de vida que está sedimentado no trabalho familiar como garantidor da sobrevivência, tanto em dimensões palpáveis e materiais quanto em termos mais simbólicos e culturais.

A terra assume valores e sentimentos que integram a moralidade da ética camponesa, pilar essencial da campesinidade. Woortmann e Woortmann (1997), na reflexão sobre o significado do trabalho da terra, consideram que este é constituído por conteúdos imateriais e simbólicos "[...] que o fazem construir não apenas espaços agrícolas, mas também espaços sociais” (WOORTMANN; WOORTMANN, 1997, p. 7). O significado simbólico do trabalho e o modelo de saber não se constituem em dimensões apartadas, ainda que operem, por vez, em domínios diferentes. Tais dimensões, em sua totalidade instituem outra forma de ver/estar o/no mundo e nele se relacionar.

A reflexão acerca da dimensão valorativa inscrita no trabalho dá margem à compreensão dos conteúdos simbólicos que o constituem e estão associados aos valores éticos e morais da campesinidade dos sujeitos sociais. Tais relações são indissociáveis ao território e expressam as significações intrínsecas à reprodução social e às estratégias de permanência e sobrevivência desses sujeitos sociais, que - para além de recurso - é condição para a existência. As relações de pertencimento e afeto construídas pelos agricultores familiares camponeses em relação à terra, lócus da vida, podem também ser traduzidas pelos sentidos espaciais que abrangem as vinculações estabelecidas entre os sujeitos sociais e a realidade espacial que vivenciam.

A compreensão do campesinato como modo de vida possibilita vislumbrar uma reflexão cultural das relações entre o homem e a terra, em que se criam valores que orientam condutas, visão de mundo e comportamentos, permeados por símbolos e significações peculiares.

Tais símbolos evidenciam traços da identidade territorial que compõem o convívio e a lida cotidiana com a terra, envolve conhecimentos ancestrais e geracionais, 
perpassados pela ideia de herança cultural construída e repassada no coletivo social. É por esse motivo que Santilli (2009) e Carvalho (2013) consideram o agricultor familiar camponês como o guardião da agrobiodiversidade, uma vez que esse saber fazer transmitido no contexto da família e/ou da comunidade é pleno de conhecimentos tradicionais que permeiam o trabalho na terra e obtém dela o sustento da família.

Tais conhecimentos, de acordo com Brandão (1999), são ancestrais, construídos no âmbito do grupo familiar ou da comunidade e transmitidos intergeracionalmente. Nas sociabilidades camponesas, o trabalho assume dimensões educativas, no sentido de preparar para a vida.

Essa discussão pode ser associada aos estudos de Almeida (2018), quando aborda os saberes ambientais construídos pelos sujeitos sociais no campo e a interdependência desses em relação ao equilíbrio da natureza. Para a autora, deve-se "[...] considerar que a devastação da vegetação natural significa a perda do conhecimento acumulado ao longo dos tempos, sobre o uso medicinal e o uso do alimento tradicional das plantas, pelas populações a elas associadas" (ALMEIDA, 2018, p. 296).

É a experiência vivida em simbiose com os tempos e movimentos da natureza que permite ao agricultor familiar camponês o acúmulo de saberes, que também são construídos e herdados no âmbito coletivo. Quando ocorre a ruptura entre a relação desses sujeitos com seus territórios de vida, resulta-se também na perda dos saberes construídos ao longo das trajetórias e vivências das mulheres e homens com a terra. Esses sujeitos sociais conhecem e respeitam o tempo da natureza, concatenando seu trabalho a este tempo.

Carvalho sublinha que esses sujeitos sociais entendem que os tempos da natureza precisam ser respeitados em suas dinâmicas e especificidades, visto que “[...] o jeito de ser e de fazer camponês acompanha e contribui para ganhar tempos no seu convívio com a natureza, [...] isso se faz pela compreensão a cada dia mais aguçada de como deve acontecer esse convívio homem-natureza" (CARVALHO, 2013, p. 6).

A relação construída por esses sujeitos com os sistemas ambientais e as práticas de cultivo e criação os tornam geograficamente integrados ao território que ajudam a produzir, tanto nos movimentos da vida cotidiana, quanto em suas práticas agrícolas de trabalho, referenciados em saberes ancestrais e familiares. O conhecimento que esses sujeitos sociais detêm sobre os ciclos da natureza, do clima, do tempo de plantar, de colher e de cuidar demarcam um elo existencial que os vinculam aos seus territórios de vida, que 
ganham significações peculiares ao modo como estes o constroem e se constroem mutuamente.

O saber fazer presente no trabalho do agricultor familiar camponês vincula-se à valorização da agrobiodiversidade, tão necessária e relevante na manutenção das diversas manifestações da vida e do trabalho na terra em um constante elo com a natureza do território vivido pelos sujeitos sociais do campo. O trabalho na terra configura-se como uma prática social intrínseca à relação da sociedade com a natureza, muito anterior ao pacote tecnológico da revolução verde - que nos países do hemisfério sul chega a partir da década de 1960. Portanto, o saber fazer que historicamente está presente no campo é anterior a essas investidas da racionalidade capitalista, materializados não somente em tecnologias e insumos da revolução verde, mas sobretudo na ideologia que a sustenta. Contudo, existem comunidades que resistem a essa lógica avassaladora de mercantilização da vida e do trabalho no meio rural e suas práticas persistem num saber fazer alheio ao ideário imposto e produzido pela revolução verde.

A modernização da agricultura e as mudanças na estrutura fundiária em Mucugê provocaram rupturas nas relações sociais entre os diferentes segmentos da sociedade do campo. A miríade de relações de troca, compadrio, trabalho familiar e solidariedade que vigorava nos espaços rurais foi substituída, em determinados espaços do município, por regimes de trabalho exploratórios e excludentes.

Contudo, embora esse processo seja hegemônico, não é homogêneo, visto que a persistência das sociabilidades e práticas tradicionais entre os agricultores familiares de Mucugê se diferem essencialmente daquelas praticadas no agrohidronegócio. Elas são constituídas por elos essenciais com o grupo familiar e o núcleo comunitário configuramse em traços marcantes na identidade territorial por eles construída. O tópico seguinte visa adentrar pelas frestas empíricas que consubstanciam a leitura do território de Mucugê, no contexto da campesinidade e do agronegócio ali presentes.

\section{Configurações territoriais de Mucugê, Chapada Diamantina-Bahia: campesinidade e agrohidronegócio}

A intensificação do povoamento da Chapada Diamantina ocorreu atrelada às atividades extrativas, sobretudo em Mucugê, principal referência da mineração de diamantes na região. A consolidação da estrutura fundiária desse município, concentrada em latifúndios, ocorreu, assim como em demais localidades brasileiras, pelo processo de apropriação das terras devolutas pelas elites econômicas locais. 
A decadência da atividade garimpeira em meados do século XX resultou num acentuado processo de migração, que marcou o esvaziamento da população de Mucugê. Tal aspecto está relacionado à desvalorização econômica das terras rurais do município, que, nas décadas seguintes, passaram a ser vendidas a preços irrisórios, ou até mesmo abandonadas. Nos anos 1980-90, essa conjuntura favoreceu a aquisição da terra por grupos migrantes oriundos do sul do país, que na atualidade se fazem presentes em Mucugê, tanto em grandes empreendimentos do agronegócio, como em pequenos empreendimentos agrícolas de médio porte e da agricultura familiar.

Salienta-se que durante período de acirramento da crise social e econômica em Mucugê, sobretudo entre as décadas de 1930 a 1970, a pobreza generalizou-se, sendo as únicas alternativas à sobrevivência os poucos cargos ofertados pelos órgãos públicos, o comércio incipiente e os pequenos cultivos da agricultura familiar camponesa nas áreas rurais e próximas ao decadente centro urbano local.

Entre as décadas de 1980-90, observa-se a inserção do agrohidronegócio no contexto local. Nesse período, o município passou a atrair grupos de migrantes sulistas e descendentes de asiáticos oriundos de Goiás, que se aproveitaram dos preços baixos das terras rurais locais e dos incentivos estatais para incorporarem as terras rurais do município em seus empreendimentos agrícolas.

Os primeiros cultivos empreendidos por grupos migrantes sulistas foram em 1984, com o plantio de trigo e soja. Contudo, não se desenvolveram em decorrência das condições climáticas locais, limitantes para essas variedades. Haesbaert (1997) aborda as repercussões territoriais desses processos migratórios na organização regional do Brasil, no contexto da modernização dos espaços agrícolas e das novas fronteiras da expansão do agronegócio nos cerrados do Nordeste, mais precisamente nas terras altas e aplainadas da Chapada Diamantina, no oeste baiano e no extremo sul do Piauí.

A expansão do capital no campo por meio do agronegócio repercutiu na formação social e identitária dessas novas áreas de expansão agrícola. Apesar da intensificação do processo de concentração fundiária nas áreas rurais do município, a década de 1990 sinaliza também um princípio de mudança na realidade local para os sujeitos sociais nativos que permaneceram no território.

Tal panorama certamente está associado à conjuntura político-econômica vigente no Brasil nesse período. A consolidação do Plano Real, em 1994, e programas de transferência de renda, a exemplo do Bolsa Escola, tiveram impactos positivos nas condições materiais de vida da população brasileira socialmente mais vulnerável. 
Ressalta-se que o aperfeiçoamento das políticas de transferência de renda no governo Lula, em 2003, oportunizou melhorias nas condições materiais de vida dessa população, o que repercutiu na segurança alimentar de milhões de pessoas no Brasil.

Esse contexto político no qual se insere a economia brasileira no final do século XX está relacionado à inserção de pequenos municípios, a exemplo de Mucugê, em programas federais de assistência social - que, de certa forma, contribuíram para a redução da pobreza extrema, predominante na realidade local nas décadas anteriores. Contudo, observa-se a permanência das contradições sociais, intrínsecas ao modo de produção capitalista. Compreende-se que, se, por um lado, tais programas de transferência de renda em escala nacional são fundamentais, por outro, isoladamente não solucionam a condição de extrema desigualdade social que assola a sociedade sob a égide do capital.

No contexto dos espaços rurais, evidencia-se como exemplo o acesso a terra, condição essencial à manutenção da vida e reprodução social de homens e mulheres do campo. A histórica concentração da terra no Brasil é encontrada na análise da estrutura fundiária de Mucugê, tendo como referência os censos agropecuários realizados em 1970 e 2017, como pode ser verificado nos gráficos da Figura 1.

Figura 1: Estrutura fundiária de Mucugê, 1970 e 2017
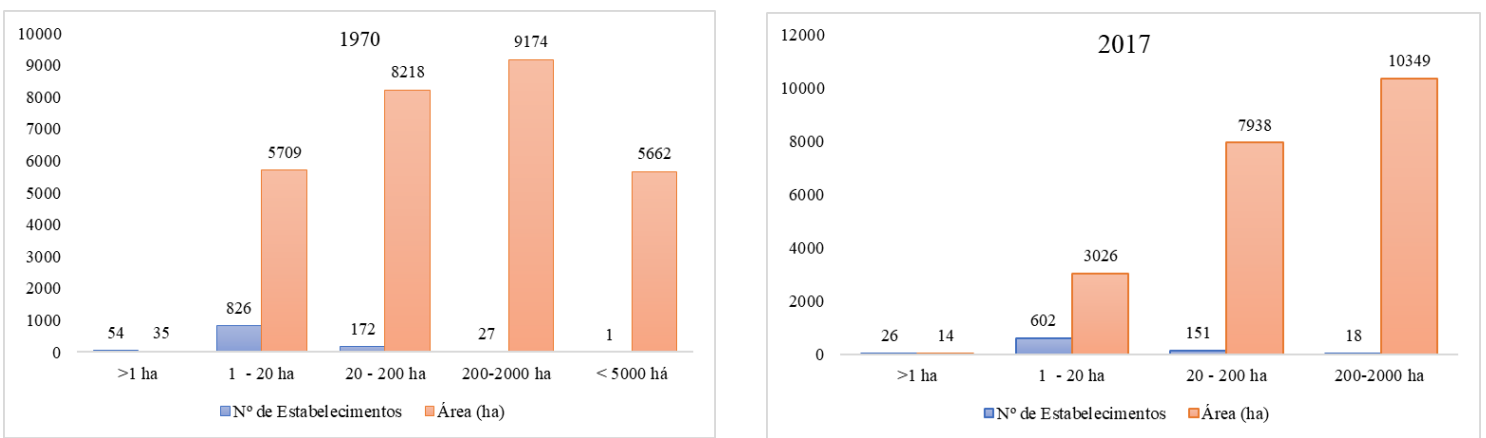

Fonte: IBGE, Censo Agropecuário, 1970 e 2017.

É possível verificar, de acordo com as informações disponibilizadas nos censos agropecuários, o predomínio absoluto dos empreendimentos rurais com área superior a 200 ha, concentradas em 27 estabelecimentos rurais em 1970, com redução para 18 em 2017. Observa-se também, tal como consideram Mitidiero Junior et al. (2017), a discrepância no nível de detalhamento do tamanho e número dos estabelecimentos.

Apesar da reconhecida relevância do IBGE e do Censo agropecuário, considerados órgão e instrumento imprescindíveis à análise do campo brasileiro, em suas 
múltiplas dimensões, considera-se que alguns critérios metodológicos, tanto aquele de organização dos intervalos espaciais, quanto o de omissão de determinados dados, não são aleatórios, ou atendem somente a uma ordem técnica.

É nesse contexto que o agrohidronegócio se territorializa nos espaços rurais de Mucugê, pautado na articulação de interesses das elites locais com o discurso desenvolvimentista do Estado e do Capital, que se alia também aos grupos empresariais externos. Tal processo é incrementado - como já citado anteriormente - pela construção da Barragem do Apertado na bacia hidrográfica do Rio Paraguaçu, obra de infraestrutura pública iniciada em 1996 e concluída em 1998 empreendida com recursos do Estado da Bahia. A utilização das águas da Barragem do Apertado para o agrohidronegócio resultou numa configuração territorial complexa nos espaços territoriais de Mucugê.

Figura 2: Configurações territoriais de Mucugê, 2020.

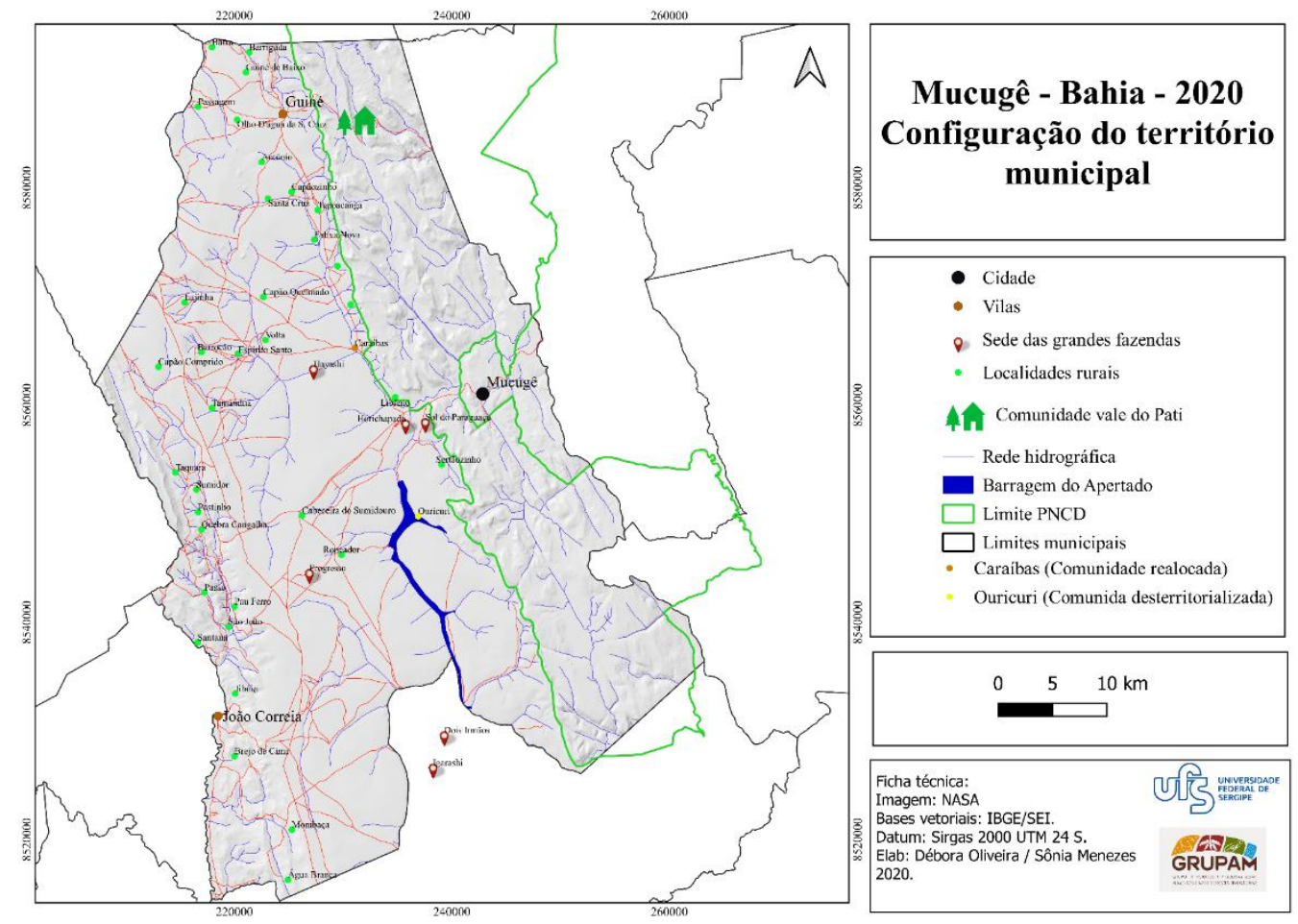

Fonte: IBGE/INPE/Pesquisa de Campo.

A leitura do mapa exposto na Figura 2 permite delinear um panorama das configurações territoriais de Mucugê. As comunidades rurais da agricultura familiar camponesa, representadas no mapa pelos localizadores amarelos, ocupam mais densamente a extensão oeste do município, situadas próximas às vilas de Guiné e João Correia - isso porque os empreendimentos agropecuários do município, cujas sedes são representadas pelos localizadores azuis, ocupam a extensão centro-sul, extrapolando o 
limite de Mucugê, com sedes e lavouras no distrito de Cascavel (Ibicoara). As configurações geoambientais dessa região do município, associadas à ação estatal com a construção da Barragem do Apertado, influenciaram a apropriação desse território pelo agrohidronegócio.

A inauguração da Barragem do Apertado acentuou o processo de dominação do território pelo agronegócio. Nos discursos que pautaram a construção dessa infraestrutura pública, imperava a ideia de que o reservatório atenderia às necessidades de abastecimento da população local e à produção agrícola familiar nos territórios rurais do município. Entretanto, além de fomentar a inserção dos empreendimentos agrocapitalistas no território, as águas da Barragem do Apertado são destinadas aos sistemas de irrigação, predominantemente estruturados em pivôs centrais implantados pelas fazendas que a circundam. Com a construção da barragem, a lâmina d'água do reservatório alagou as terras de uma comunidade rural, Ouricuri, que foi realocada para a comunidade Caraíbas. Além disso, a barragem também ocupou áreas relativamente planas e extinguiu formas tradicionais de cultivos de arroz nas margens férteis desse trecho do Rio Paraguaçu, e repercutiu na redução drástica desse cultivo tradicional da agricultura familiar camponesa de Mucugê.

A Tabela 1, apresentada em sequência, evidencia o avanço vertiginoso dessa monocultura no município, por meio do levantamento de dados acerca da produção de alimentos tradicionais da agricultura familiar camponesa local, nos censos agropecuários realizados entre os anos de $1970-2017$.

Tabela 1: Quantidade produzida $(\mathrm{t})$ de cultivos tradicionais e crescimento da batata inglesa em Mucugê, $1970-2017$.

\begin{tabular}{c|c|c|c|c|c|c}
\hline Ano & Arroz & Cana de açúcar & Mandioca & Milho & Feijão & Batata Inglesa \\
\hline 1970 & 254 & 1339 & 2291 & 167 & 106 & 1 \\
1980 & 233 & 1028 & 41 & 10 & 25 & - \\
1995 & 141 & 6615 & 369 & 909 & 824 & 7885 \\
2006 & 574 & 1243 & 435 & 1231 & 1612 & 43066 \\
2017 & 77 & 177 & 98 & 201 & 1017 & 35465 \\
\hline
\end{tabular}

Fonte: IBGE, Censos Agropecuários de 1970, 1980, 1995, 2006 e 2017.

Em síntese, verifica-se que os alimentos tradicionais da agricultura familiar camponesa no município são produzidos nas pequenas propriedades, que, mesmo com oscilações em relação à quantidade, mantiveram-se nas décadas elencadas no levantamento. No entanto, o acelerado crescimento do monocultivo da batata inglesa 
verificado em 1995 e intensificado nos anos de 2006 e 2017 evidencia o avanço do agrohidronegócio local e, consequentemente, a repercussão negativa nos cultivos tradicionais, com redução na quantidade produzida.

$\mathrm{Na}$ região central, o investimento estatal na Barragem do Apertado permitiu a expansão do agrohidronegócio, tendo em vista que os grandes empreendimentos rurais no município usufruem de infraestruturas públicas e, com os incentivos e consentimentos estatais, mantêm privilégios à base dos investimentos públicos (THOMAZ JUNIOR, 2010).

Tal cenário se concretiza na realidade dos espaços rurais de Mucugê, visto que dos seis grandes empreendimentos rurais que dominam o agrohidronegócio no município, somente um não utiliza água da Barragem do Apertado para irrigação, pois suas lavouras estão localizadas em uma área distante dessa infraestrutura, o que inviabiliza a logística de utilização dos recursos hídricos.

Dentre os empreendimentos locais, salienta-se que dois não possuem sede no interior dos limites municipais de Mucugê, pois estas estão localizadas no distrito de Cascavel, pertencente ao município de Ibicoara. No entanto, ambos os empreendimentos possuem extensas áreas cultivadas na região centro sul de Mucugê. Observa-se que as lavouras desses empreendimentos estão situadas próximas à rede hidrográfica, constituída em sua maioria por rios perenes que - atrelados ao relevo aplainado e aos solos profundos, característico dos gerais - compõem condições favoráveis para ampliar o potencial agricultável desse território.

O território no contexto do agrohidronegócio pode ser lido como um recurso para a reprodução e expansão capitalista. Essa afirmação está pautada na abordagem de Gotmann (2012 [1975]), quando analisa as relações de poder que emanam da simbiose entre a política e o espaço geográfico, delineando o território. No âmbito do agrohidronegócio, o território é, simultaneamente, recurso e condição de reprodução de relações de poder e controle da terra.

Afiançada nessas reflexões, compreende-se que os territórios rurais de Mucugê são manipulados por interesses de segmentos externos, como os empreendimentos capitalistas e o Estado. Contrariando os discursos desenvolvimentistas que subsidiam o domínio do território por esses grandes empreendimentos do agronegócio, constata-se, mediante o levantamento de dados sociais e econômicos locais, que toda a riqueza aparentemente produzida por esse setor está muito longe de repercutir na melhoria das condições materiais de vida da população local. Tal fato se evidencia na comparação dos 
índices econômicos de Mucugê com os municípios que apresentam economia mais dinâmica da Bahia - a saber: Salvador, Feira de Santana e Vitória da Conquista, utilizando-se de informações sobre IDHM, rendimento mensal per capita até 1/2 salário mínimo, PIB per capita e população estimada em 2019. Essa comparação é ilustrada no mapa apresentado na Figura 3.

Figura 3: Análise comparativa dos indicadores socioeconômicos dos municípios de Mucugê, Vitória da Conquista, Feira de Santana e Salvador.
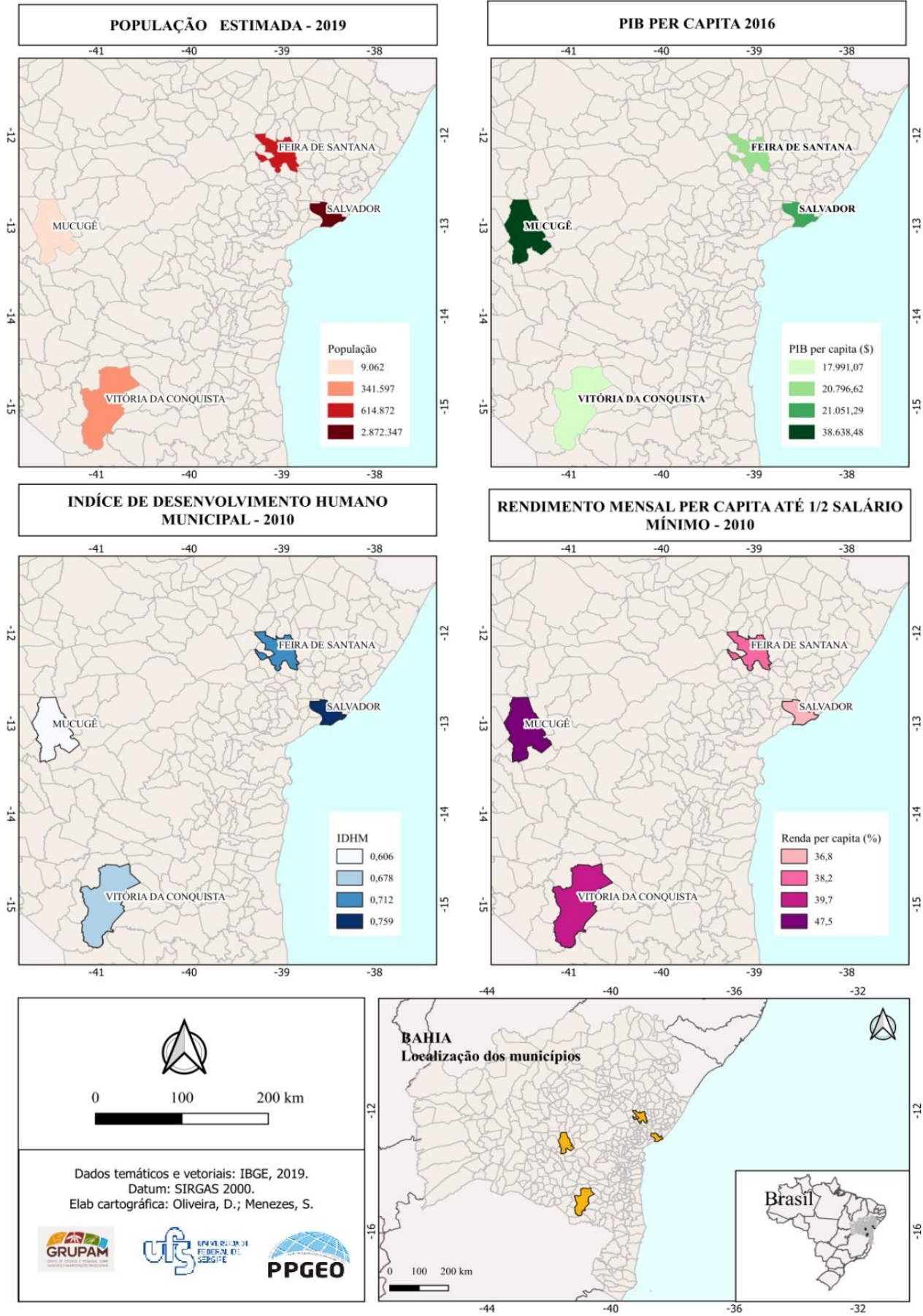

Fonte: IBGE, 2019. 
O primeiro mapa da sequência apresenta a estimativa populacional dos municípios elencados para o ano de 2019 - que em Mucugê corresponde a 9.062 pessoas; em Vitória da Conquista, 341.597; em Feira de Santana, 614.872; e em Salvador, 2. 872347 pessoas. Quando associado aos mapas seguintes, sobretudo, àquele relativo ao PIB per capita, constituído pela razão entre o PIB e a população total de um local em um mesmo intervalo de tempo, observa-se como esse índice se constitui como um indicativo da concentração da renda em Mucugê.

O PIB per capita de Mucugê de 2019, que corresponde a aproximadamente 38 mil reais, ultrapassa os resultados dos demais municípios elencados na comparação, chegando próximo ao dobro do PIB per capita registrado em Salvador, cerca de 21 mil reais. Sublinha-se ainda que Mucugê registra um quantitativo populacional substancialmente inferior aos demais. É notório que, analisado isoladamente, esse indicativo econômico não contempla as condições materiais de vida da população local e evidencia o caráter concentrador do crescimento econômico associado ao agrohidronegócio.

Essas contradições são evidentes no descompasso entre o PIB per capita e as reais condições econômicas da população, retratadas nos demais dados. A pretensa superioridade desse índice contrasta com o baixo IDHM de Mucugê (0.606) e o elevado percentual da população que vive com até $1 / 2$ salário mínimo, cerca de 47,5\%, tal como se observa nos dois mapas que encerram a sequência.

Para além dos dados apresentados, a realidade em si evidencia essas contradições sociais, compreende-se que a concentração da terra, associada à dependência das comunidades rurais locais em relação ao trabalho assalariado nos estabelecimentos rurais, repercute nesses índices contraditórios. Essa condição não o descaracteriza enquanto sujeito da campesinidade, do contrário, é necessária para sua reprodução, visto que sua permanência na terra está associada a essa e outras estratégias que esses sujeitos sociais constroem para garantir o sustento e as necessidades materiais do núcleo familiar.

A memória do processo de constituição dos latifúndios ainda é presente para os sujeitos sociais que vivenciaram tal processo, pois a terra, que até então era o patrimônio da família, tornou-se mercadoria para o suprimento das demandas de acumulação do capital.

A leitura da campesinidade não significa “[...] tratar o camponês como um 'pequeno produtor', objeto de uma análise objetiva de sua objetividade, mas tentar uma interpretação subjetiva - pois se trata da minha perspectiva - de sua subjetividade" 
(WOORTMANN, 1990, p. 12). Os sentidos da terra para esses sujeitos são construídos cotidianamente na relação destes com o sítio, onde os agricultores familiares camponeses plantam, colhem e cuidam de suas criações. Esse território ganha a plenitude da vida, da autonomia e da soberania do trabalho na terra.

Desse modo, na contramão da hegemonia capitalista nos espaços rurais de Mucugê, persistem territorialidades, outrossim são criadas novas territorialidades pelos agricultores. O cultivo e a comercialização de alimentos na feira e nas quitandas locais configuram-se como práticas contra hegemônicas que fortalecem a campesinidade e contribuem para a geração de renda e a reprodução familiar das comunidades rurais.

Os homens e as mulheres da agricultura familiar camponesa persistem na terra e no seu modo de vida, e nesse processo elaboram territorialidades, lidas com estratégias de permanência e reprodução social, num esforço de valorização da produção e fortalecimento das redes de sociabilidade informal, pautadas no comércio e no consumo de alimentos tradicionais. Exemplo disso é a produção, comercialização e o consumo do doce de marmelo, produzido artesanalmente por mulheres do Paiol, na zona rural do município. O trabalho na lavoura é realizado de forma familiar, do preparo da terra à colheita, além da feitura e comercialização do doce (Figura 4).

Figura 4: Lavoura, fruto e doce de marmelo produzido artesanalmente no Paiol

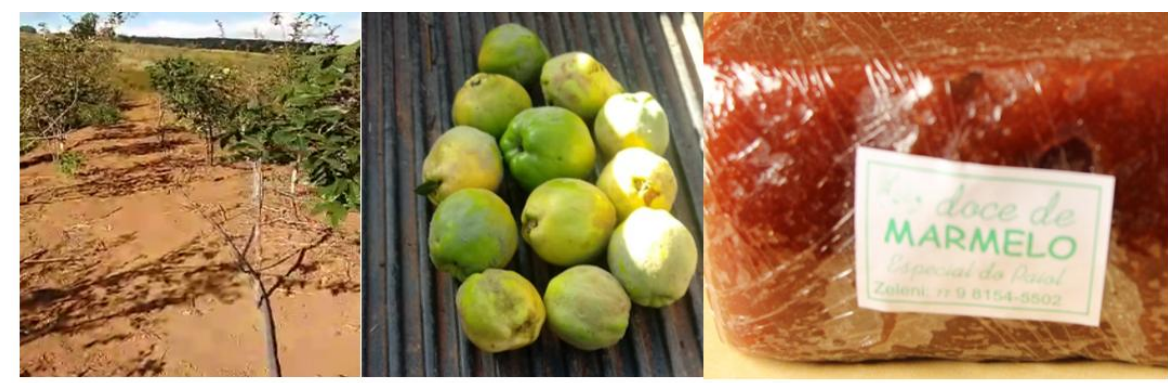

Fonte: Pesquisa de campo, 2021.

Numa lógica adversa àquela imposta pelo agrohidronegócio, pautada nos monocultivos, latifúndios e exploração do trabalho, persistem territorialidades e saberes resilientes da agricultura familiar camponesa. Trata-se de territórios residuais em que predomina a agrobiodiversidade, conforme discute Carvalho (2013). A as fotografias apresentadas na Figura 5 ilustram a diversidade dos cultivos produzidos no âmbito da agricultura familiar camponesa no município: 
Figura 5: Cultivos produzidos na agricultura familiar camponesa de Mucugê, 2019

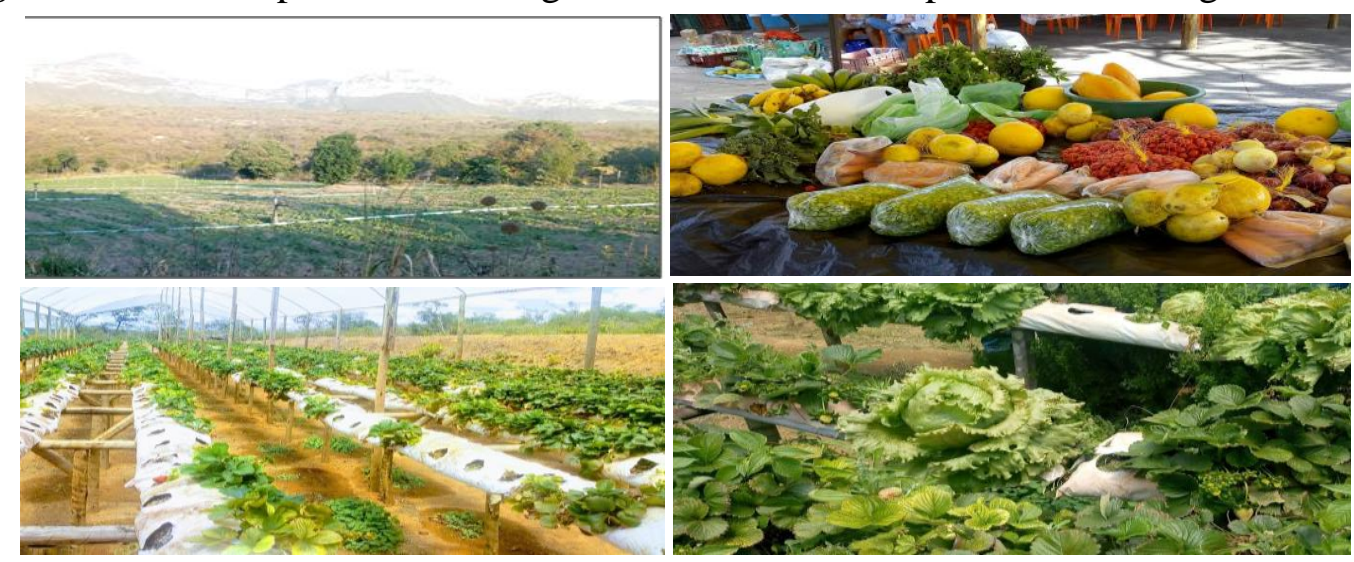

Fonte: Pesquisa de campo, 2019.

A posse da terra, associada ao saber fazer no trabalho da terra é condição imprescindível para a autonomia e a liberdade do sujeito da agricultura familiar camponesa. Em face disso, Woortmann e Woortmann (1997, p. 44) declaram: “[...] Ser sitiante, ser dono da terra é condição básica de ser liberto, juntamente com o domínio tanto cognitivo como simbólico do saber que orienta o processo de trabalho". A labuta cotidiana na terra concede ao agricultor familiar camponês um profundo conhecimento em relação à natureza e ao equilíbrio dos sistemas ambientais com os quais se relaciona.

\section{Considerações finais}

Considerando a historicidade da Chapada Diamantina, percebe-se que as relações de poder que regem/regeram esse território permanecem em conteúdo, ainda que as formas tenham sido alteradas. O poder dos coronéis do passado, atualmente se reproduz sob a forma do latifúndio e do agronegócio, que subjuga territórios e sujeitos sociais.

A dimensão simbólica do trabalho e da terra para o agricultor familiar camponês pode ser tecida sobre outras vertentes analíticas que distam dos consagrados debates do mundo rural. Ao conjecturar sobre o saber fazer que os sujeitos sociais constroem no campo, Woortmann e Woortmann (1997) priorizam a leitura dessa realidade sob o prisma de quem a vivencia. O significado da terra e, por extensão, dos territórios para esses grupos sociais envolve os valores inscritos em seu modo de vida e cotidianidade.

No entanto, mesmo em face de condições estruturantes desfavoráveis, em que há o predomínio do agrohidronegócio no território, persistem nos espaços rurais de Mucugê grupos familiares que, por meio da agricultura familiar camponesa, constroem suas geograficidades em suas maneiras de vivenciar cotidianamente o território. 
Em face disso, a identidade territorial desses grupos se mescla, ressignifica e resiste. Criam-se, então, territorialidades que, além de constituírem-se como uma relação de pertencimento e afeto na terra, compõem também estratégias de convivialidade e reprodução social.

\section{REFERÊNCIAS}

ALMEIDA, M. G. Geografia Cultural - um modo de ver. Goiânia: Gráfica UFG, 2018.

BONNEMAISON, J. Viagem em torno do território. In: ROSENDHAL, Z.; CORRÊA, R. L. (Org.). Geografia cultural: um século (3). Rio de Janeiro: EdUERJ, 2002. p. 83131.

BRANDÃO, C. R. O trabalho de saber: cultura camponesa e escola rural. 2. ed. Porto Alegre: Sulina, 1999.

CARVALHO, H. M. O camponês, guardião da agrobiodiversidade. Boletim DATALUTA, 2013. Disponível em: http://www2.fct.unesp.br/nera/artigodomes/7artigodomes_2013.pdf Acesso em: 25 de fev. 2021.

FERNANDES, B. M. Cuando la agricultura familiar es campesina. In: FLOR, F. H.; HOUTART, F.; LIZÁRRAGA, P. (eds.). Agriculturas campesinas em

Latinoamérica: propuestas y desafíos. Quito: Editorial IAEN, 2014. p. 19-34.

GOTMANN, J. A evolução do conceito de território. Boletim Campineiro de Geografia, v. 2, n. 3, 2012 [1975]. Tradução: Isabela Fajardo e Luciano Duarte. Revisão: Fabricio Gallo.

HAESBAERT, R. Des-territorialização e identidade : a rede "gaúcha" no Nordeste. Niterói: EDUFF, 1997

HAESBAERT, R. Identidades territoriais. In: ROSENDAHL, Z. \&CORREA, R. L Manifestações da cultura no espaço. Rio de Janeiro: Ed. UERJ, 1999, p.169-190. INSTITUTO BRASILEIRO DE GEOGRAFIA E ESTATÍSTICA (IBGE).Censo agropecuário. Disponível em https://sidra.ibge.gov.br/Acervo?nivel=6\&unidade=2921906\#/S/Q. Acesso em $28 \mathrm{de}$ nov. de 2019.

MENDONÇA, M. R.; MESQUITA, H. A. O agrohidronegócio no cerrado goiano: a construção das (re)existências. In: ENCUENTRO LATINOAMERICANO CIENCIAS SOCIALES Y REPRESAS, 1; ENCONTRO BRASILEIRO DE CIÊNCIAS SOCIAIS E BARRAGENS, 2. Anais... Salvador, 2007.

MENEZES, S. S. M. A força dos laços de proximidade na tradição e inovação no/do território sergipano das fabriquetas de queijo. Tese de Doutorado em Geografia. 
Núcleo de Pós Graduação em Geografia, Universidade Federal de Sergipe, São Cristóvão, SE, 2009.

MITIDIERO JUNIOR, M. A.; BARBOSA, H.; SÁ, T. Quem produz comida para os brasileiros? 10 anos do Censo Agropecuário 2006. PEGADA-A Revista da Geografia do Trabalho, v. 18, n. 3, 2017.

OLIVEIRA, A.U. Agricultura camponesa no Brasil. 4.ed. São Paulo: Contexto, 2001. OLIVEIRA, A.U. Barbárie e modernidade: as transformações no campo e o agronegócio no Brasil. Revista Terra Livre. São Paulo: AGB, n.21, p.113-156, $2^{\circ}$ sem. 2003.

RAFFESTIN, C. Por uma Geografia do Poder. São Paulo: Ática, 1993.

SANTILLI, J. Agrobiodiversidade e direito dos agricultores. São Paulo: Editora Petrópolis, 2009.

THOMAZ JUNIOR, A. O agrohidronegócio no centro das disputas territoriais e de classe no Brasil do século XXI. Campo-território: revista de geografia agrária, 2010.

THOMAZ JUNIOR, A. Degradação Sistêmica do Trabalho no Agrohidronegócio. Mercator, Fortaleza, v. 16, e16020, 2017

WOORTMANN, E; WOORTMANN, Klaus. O Trabalho da Terra: A lógica e a simbólica da lavoura camponesa. Brasília. Ed. UNB. 1997.

WOORTMANN, K. Com parente não se neguceia: o campesinato como ordem moral. Anuário Antropológico. Rio de Janeiro, 87. 1990. 